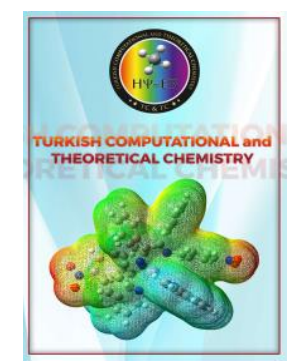

Received: 02.09.2019
Turkish Computational and Theoretical Chemistry

Turkish Comp Theo Chem (TC\&TC)

Volume(Issue): 4(1) - Year: 2020 - Pages: 12-23

e-ISSN: 2602-3237

https://doi.org/10.33435/tcandtc. 614263

Accepted: 10.05 .2020

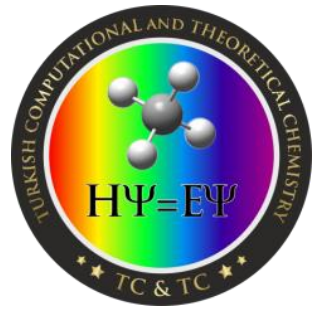

Research Article

\title{
QSAR and Molecular Docking Studies of novel thiophene, pyrimidine, coumarin, pyrazole and pyridine derivatives as Potential Anti-Breast Cancer Agent
}

\section{Momohjimoh Ovaku IDRIS ${ }^{l}$, Stephen Eyije ABECHI, Gideon Adamu SHALLANGWA, Adamu UZAIRU}

Department of Chemistry, Ahmadu Bello University Zaria-Nigeria

\begin{abstract}
Quantitative Structure Activity Relationship (QSAR) and molecular docking studies were carried out on some novel compounds to generate a good QSAR model that relate the anti-breast cancer activity values with their molecular structure. Genetic Function Algorithm (GFA) and Multiple Linear Regression Analysis (MLRA) were employed to select the descriptors that were used to build the models. The best model built was found to have statistical validation values of squared correlation coefficient $R^{2}=0.9845$, adjusted squared correlation coefficient $R_{a d j}{ }^{2}=0.9814$, cross validation coefficient $Q_{C v}{ }^{2}=0.9763$ and an external squared correlation coefficient $R_{\text {ext }}{ }^{2}=0.8240$ which was used to confirm the validation of the model. The docking results showed that ligands 12 with binding energy $\left(-9.3 \mathrm{kcalmol}^{-1}\right)$ have the highest binding affinity when compared to the reference drug doxorubicin with binding energy $\left(-6.8 \mathrm{kcalmol}^{-1}\right)$. The stability and robustness of the built model showed that new anti-breast cancer agents can be design from these derivatives.
\end{abstract}

Keywords: Breast Cancer, QSAR model, Model Validation, Binding Affinity.

\section{Introduction}

Cancer is the abnormal growth of the cell and is the second leading cause of death after circulatory diseases. The World Health Organisation (WHO) predicted 15 million death cases by the year 2020 unless a new measure is taking [1].

Breast cancer is the most common cancer in women [2], it usually develop from breast tissue. In Nigeria, cervical cancer was the commonest cause of cancer- related deaths among women for several decades but breast cancer is now the leading cause of cancer related deaths among Nigerian women [3].

Doxorubicin is one of the numerous hypothetical anti-cancer drug used in treatment of all kinds of cancer, the recent emergence of resistance to this available anti-cancer drug calls for immediate need to develop new anti-cancer agents. Development of new drug is by trial and error approach and this is time consuming.

\footnotetext{
${ }^{1}$ Corresponding Authors

e-mail: eedrismj@gmail.com
}

QSAR is computational method that decode the relationship between the structure of a molecule and the activity of such molecule in a numerical form [4]. Application of this technique have been employed in drug discovery to design new drugs and also improved the existing ones because its time saving and lesser cost.

Therapeutic treatment of cancer usually focuses on targeting critical cellular processes involved in DNA replication and cell division. This method consist of different set of agents each targeting different pathways and enzymes. One class of agents, predominantly effective at disrupting cancer cell growth, are drugs targeting DNA topoisomerases [5], this is why this work uses top2A as the receptor.

DNA topoisomerases are a family of enzymes originate in the nucleus and the mitochondria that are responsible for maintaining DNA topology [6]. DNA topology refers to the relationship between 
the two strands of the double helix and includes the concept of supercoiling [7].

Type II topoisomerases (Topo2 $\boldsymbol{\alpha}$ ) form a transient double-strand DNA break in one segment which can pass one DNA segment to another through the break prior to ligating the cleaved DNA ends. Type II topoisomerases found in living organisms is divided into IIA and IIB [8]. They vary in terms of structure, mechanism and cofactor. Type II enzymes works either to enhance different chromosomes (e.g., for chromosome segregation and unknotting) or sections of the same chromosome (e.g., during transcription and replication) [6].

Molecular docking is a computational technique used to predict accurately the binding score of a complex (ligand-receptor interaction) [9], information derived can then be used to evaluate the energy profiling, such as binding energy, bond length, bond strength and binding constant. The QSAR models were developed using Drug Theoretic and Cheminformatic (DTC) Laboratory software tool while the docking studies was achieved using the discovery studio and Auto-duck Vina of the PyRx.

The aim of this work is to generate a robust QSAR model and perform a flexible docking studies on those aforementioned compounds that would serve as raw data to the pharmacologist and pharmacist for rational drug designing (structurebased-drug development) of new anti-breast cancer agents with better efficacy [10].

\section{Materials and Methods}

\subsection{Data Collection and Activity Evaluation}

The data set used in this work was collected from the literature [11]. The structure of the compounds were drawn with Chem Draw software and optimized with Spartan software to remove the strained energy.

The biological activities of the compounds were provided in the literature as fifty percent growth inhibition concentration $\left(\mathrm{GI}_{50}\right)$, they were converted to logarithm unit $\left(\mathrm{pGI}_{50}\right)$ using the equation 1 below for simplicity. The structures of the compounds and their biological activities were presented in Supp. Table S1.

$$
\mathrm{pGI}_{50}=\left(\mathrm{GI}_{50} \times 10^{-3}\right)
$$

\subsection{Molecular Descriptors Calculation and Data Pretreatment}

The two dimensional structures (2D) of the compounds presented in the Table 1 were drawn with Chemdraw software version 12.0.2 [12], they were exported to the Spartan 14 V1.1.4 Wave Function programming package software to view the spatial conformers of the compounds, i.e, three dimensional (3D) structures. These 3D structures were geometrically optimized using Density Functional Theory (DFT) method, utilizing the (B3LYP/6-31G*) hybrid function known as Becke's three parameter exchange functional (B3) hybrid with Lee, Yang and Parr correlation functional (LYP) [13, 14]. The optimized molecules in Spartan files format were converted to SD format and saved which was subsequently exported to PaDEL-Descriptor software V2.20 [15] to calculate the molecular descriptors.

Molecular descriptors are numerical description of molecules. The descriptors of all the 34 molecules were calculated using PaDEL-Descriptor software V2.20 and a total of 1875 molecular descriptors were calculated.

The data set was pre-treated with data pretreatment software from Drug Theoretics and Cheminformatics Laboratory (DTC Lab) so as to remove uninformative data [16].

\subsection{Model Generation and Validation}

To generate a good QSAR model, the pretreated data set was divided into two subset (training and test set), using the data division software from DTC Lab [17-19]. The training set comprised of $70 \%$ of the total molecules and the rest of the molecules were test set. The training set was used to build the models employing GFA-MLR method from the material studio and the test set were used to validate the model built [20]. The fitness score of the models were evaluated using the leave one out (LOF) giving by the equation 2 .

$$
\mathrm{LOF}=\frac{S E E}{\left(1-\frac{C+d^{*} P}{M}\right)^{2}}
$$

Where SEE is the standard error of estimation, $\mathrm{C}$ is the number of terms in the model, $d$ is a user defined smoothing parameter, $\mathrm{P}$ is the total number of descriptors contained in the model and $\mathrm{M}$ is the number of training set data. SEE is defined by equation (3)

$$
\mathrm{SEE}=\sqrt{\frac{\left(Y_{\exp }-Y_{p r e}\right)^{2}}{N-P-1}}
$$

Where $Y_{\text {exp }}$ and $Y_{\text {pre }}$ are the experimental activity and the predicted activity in the training set 
respectively [21]. The squared correlation coefficient is a validation test used to compare the predicted and experimental activities. The closer $\mathrm{R}^{2}$ value is to 1.0 indicates a good and strong model. $\mathrm{R}^{2}$ is expressed as:

$$
\mathrm{R}^{2}=1-\left[\frac{\Sigma\left(Y_{\text {exp }}-Y_{\text {pred }}\right)^{2}}{\sum\left(Y_{\text {exp }}-Y_{\text {training }}\right)^{2}}\right]
$$

Where $Y_{\text {exp }}, \quad Y_{\text {pred }}$ and $\bar{Y}_{\text {training }}$, are respectively the experimental activity, the predicted activity, and the mean experimental activity of the samples in the training set. The $\mathrm{R}^{2}$ value alone cannot justify the goodness of the model as such it was adjusted to give a stable and reliable value. If the difference between the $\mathrm{R}^{2}$ and $R_{a d j}^{2}$ value is less than 0.3, it indicates that the number of descriptors used in building the model are appropriate and the model would be accepted but a value greater than 0.3 will be rejected. The adjusted $\mathrm{R}^{2}$ is givens by:

$$
R_{a d j}^{2}=\frac{R^{2}-k(n-1)}{n-P+1}
$$

Where $\mathrm{k}$ is the number of descriptors in the model and $\mathrm{n}$ is the number of training set compounds [20]. Cross-validation test is used to measure the predictive ability of the model. The cross validation coefficient $Q_{\sigma V}^{2}$ is defined as:

$Q_{c v}^{2}=1-\left[\frac{\sum\left(Y_{\text {exp }}-Y_{\text {pred }}\right)^{2}}{\sum\left(Y_{\text {exp }}-P_{\text {training }}\right)^{2}}\right]$

To be certain that the built model is firm and not infer by chance, the model is further put to an external validation test. This is calculated as thus;

$R_{\text {test }}^{2}=1-\frac{\Sigma\left(Y_{\text {pred }} d_{\text {test }}-Y_{\text {exptest }}\right)^{2}}{\sum\left(Y_{\text {pred }} d_{\text {test }}-P_{\text {training }}\right)^{2}}$

Where $Y_{\text {pred }}$ is the predicted activity, $Y_{\text {exp test }}$ is the experimental activity of the test set and $\bar{Y}_{\text {training }}$ is the mean activity of the training set [21].

\subsection{Y- Randomization Test}

Y-randomization test is a test performed on the training data set to ascertain that the descriptors used to build the models were appropriate and to also know how strong the built model is. The test was done by randomly mixing the activity data which was taking as the dependent variable and the descriptors as the independent variable. After several trials, the new QSAR models generated were found to have very low $\mathrm{R}^{2}, \mathrm{Q}^{2}$ and a randomized square correlation coefficient $\left(c R_{p}{ }^{2}\right)$ with value greater than $(0.5)$ that confirmed the robustness of the models.

$c R_{p}^{2}=R \times\left[R^{2}-\left(R_{r}\right)^{2}\right]^{2}$

Where $c R_{p}{ }^{2}$ is the coefficient of determination for Y-randomization and $R_{r}$ is the average ' $\mathrm{R}$ ' of random models [20].

\subsection{Mean Effect of the Model}

The mean effect of the model is a test used to show the comparative importance of each descriptors present in the model. This was calculated using equation (11)

$\mathrm{ME}=\frac{B_{j} \sum_{i}^{\mathrm{n}} D_{j}}{\sum_{j}^{\mathrm{m}}\left(B_{j} \sum_{i}^{\mathrm{n}} D_{j}\right)}$

Where $B_{j}$ is the coefficient of the descriptor $j$ in the model, $D_{j}$ is the value of each descriptor in the data matrix for each of the training set data, $m$ and $n$ are respectively the number of descriptors that appears in the model and the number of molecules in the training set [22].

\subsection{The Predictive Power of the Model}

The selectivity, efficacy and potency, (SEP) of the developed models were evaluated using both internal and external validation parameters, its applicability domain and the Variance Inflation Factor (VIF). Table 2 below show clearly the standard validation parameters for a generally acceptable QSAR model [23].

The applicability domain is a test performed on the training set to confirm the robustness of the built models. The leverage approach was employed to describe the applicability domain of the QSAR model [24]. Leverage of a given chemical compound is defined as:

$$
l_{i}\left[X_{i}\left(X^{T} X\right)^{-1} X_{i}^{T}\right]
$$


Table 2. Minimum Validation Parameters for generating good QASR model.

\begin{tabular}{|c|c|c|}
\hline $\begin{array}{l}\text { Validation } \\
\text { parameter }\end{array}$ & Meaning & Values \\
\hline$R^{2}$ & $\begin{array}{l}\text { Coefficient of } \\
\text { determination }\end{array}$ & $\geq 0.6$ \\
\hline$P_{95 \%}$ & $\begin{array}{c}\text { Confidence } \\
\text { interval at } 95 \% \\
\text { confidence level }\end{array}$ & $<0.06$ \\
\hline$Q_{c v^{2}}{ }^{2}$ & $\begin{array}{l}\text { Cross-validation } \\
\text { coefficient }\end{array}$ & $>0.5$ \\
\hline$R^{2}-Q_{c v}{ }^{2}$ & $\begin{array}{c}\text { Difference } \\
\text { between } R^{2} \text { and } \\
Q_{C v}{ }^{2}\end{array}$ & $\leq 0.3$ \\
\hline$N_{\text {ext. test set. }}$ & $\begin{array}{c}\text { Minimum } \\
\text { number of } \\
\text { external test sets }\end{array}$ & $\geq 5$ \\
\hline$R_{\text {test }}{ }^{2}$ & $\begin{array}{l}\text { Coefficient of } \\
\text { determination for } \\
\text { external test set }\end{array}$ & $\geq 0.6$ \\
\hline$c R_{p}^{2}$ & $\begin{array}{l}\text { Coefficient of } \\
\text { determination for } \\
Y \text {-randomization }\end{array}$ & $>0.5$ \\
\hline
\end{tabular}

Where $l_{i}$ is the leverage of each molecule is, $X_{i}$ is the descriptor row-vector of the query compound $i$, and $X$ is the $(\mathrm{m} \times \mathrm{n})$ descriptor matrix of the training set molecules used in building the model. The warning leverage $\left(l_{i}^{*}\right)$ showed the molecule(s) that exceeded the leverage value. This can be calculated using equation 13 .

$$
l_{i}^{*}=\frac{3(k+1)}{n}
$$

Where is $n$ the number of training set molecules and $\mathrm{k}$ is the number of descriptors in the model. The Williams plot was the plot of standardized residual against leverage employed to elucidate the relevance area of the model in terms of chemical space. Any data in the plot with value greater than \pm 3 would be treated as outlier.

The VIF is a measure of multi-collinearity between the descriptors used to generate the model and is expressed as:

$$
\mathrm{VIF}=\frac{1}{1-R^{2}}
$$

Where $R^{2}$ is the correlation coefficient of the multiple regression between the variables within the model. A good and acceptable model would have its VIF values ranges from 1-5.

\subsection{Docking Studies}

Molecular docking was carried out to evaluate the binding affinity of the ligands to the receptor. The 3D-structure of the receptor (Top2 $\boldsymbol{\alpha}$ ) was downloaded from RCSB PDB (http://www.rcsb.org/pdb/home/ home.do) with code 4fm9 [25]. Removable residue like cofactors, ligands, water molecule were found absent. The ligands were prepared by converting the optimized 3D structures from SD format to protein data bank format (pdbqt). The prepared receptor and ligands were docked together with the Auto Dock Vina of the PyrX software and the complex was visualized utilizing the discovery studio software visualizer. Figure 1 shows the 3D structure of the receptor (topoisomerase).

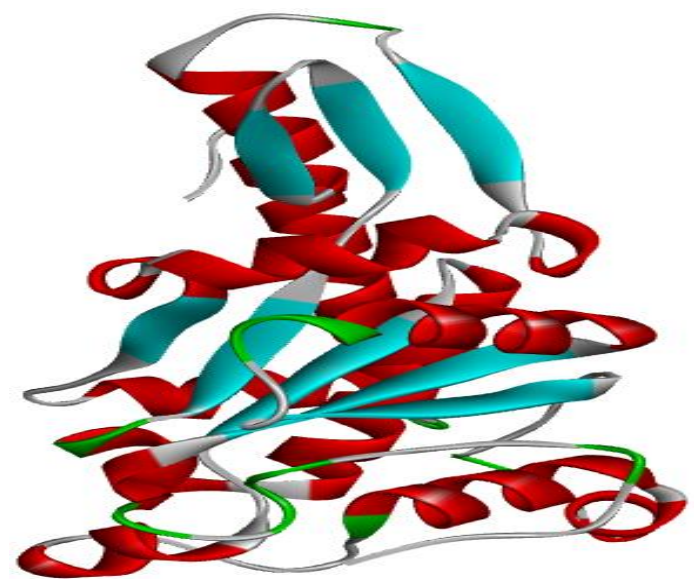

Figure1. 3D structure of Topoisomerase (ii).

\section{Results and Discussion}

The 34 compounds comprising of some novel thiophene, pyrimidine, coumarin, pyrazole and pyridine derivatives were subjected to QSAR and molecular docking studies to generate good QSAR model with better activity against breast cancer. The compounds were optimized, their descriptors were calculated and they were divided into training and test set employing the Kennard-Stone method of data division [19]. The training data set were used to develop the model and the test data set were used to validate the built model. The Genetic Algorithm and multi Linear Regression (GA-MLR) from the material studio was employed to build the models and three models were built. Table 3 present the statistical validation parameters of the built models, the first model was carefully chosen and reported as the best model because of its statistical validation values when compared to the minimum required validation parameters presented in Table 2.

Table 4 present the experimental, predicted and residual activity values for both the training and test set. The low residual values (difference between the 
Turkish Comp Theo Chem (TC\&TC), 4(1), (2020), $12-23$

Momohjimoh Idris OVAKU, Stephen Eyije ABECHI, Gideon Adamu SHALLANGWA, Adamu UZAIRU

experimental activity and predicted activity) indicates the high predictive power of the built model.

Table 3. Validation parameters of the built models.

\begin{tabular}{ccc}
\hline Validation parameters & Meaning & Values \\
\hline$R^{2}$ & Coefficient of determination & 0.9845 \\
$P_{95 \% 6}$ & Confidence interval at $95 \%$ confidence level & 0.0195 \\
$Q_{c v}{ }^{2}$ & Cross-validation coefficient & 0.9763 \\
$R^{2}-Q_{c v}{ }^{2}$ & Difference between $R^{2}$ and $Q_{c v}{ }^{2}$ & 0.0082 \\
$N_{\text {ext test set. }}{ }^{2}$ & Minimum number of external test sets & 11 \\
$R_{t e s t}{ }^{2}$ & Coefficient of determination for external test set & 0.8240 \\
$c R_{p}{ }^{2}$ & Coefficient of determination for $Y$-randomization & 0.8200 \\
\hline
\end{tabular}

Best Model

pGI $_{50}=0.709363893 *$ GATS8 $-4.252846824 * \operatorname{maxHBd}-\mathbf{0 . 0 6 3 1 5 0 0 1 8} *$ TDB10p $-0.153565552 *$ RNCS + 4.211504042.

Table 4a: Experimental, Predicted and Residual Activity values training set.

\begin{tabular}{lccc}
\hline S/N & Experimental Activity & Predicted activity & Residual activity \\
\hline 2 & 1.5670 & 1.5673 & -0.0003 \\
3 & 2.5229 & 2.4293 & 0.0936 \\
4 & 1.3778 & 1.4520 & 0.0742 \\
5 & 1.2899 & 1.3575 & -0.0676 \\
7 & & \\
10 & 1.3188 & 1.3985 & -0.0797 \\
11 & 4.0458 & 4.0494 & -0.0037 \\
12 & 1.4214 & 1.5261 & -0.1047 \\
13 & 1.4056 & 1.3025 & 0.1031 \\
& 1.3947 & 1.3116 & 0.0831 \\
14 & 1.4802 & 1.4158 & 0.0644 \\
16 & 1.5376 & 1.4644 & 0.0732 \\
17 & 1.4450 & 1.4122 & 0.0328 \\
19 & 1.3546 & 1.3360 & 0.0186 \\
20 & 1.4353 & 1.3687 & 0.0666 \\
21 & 1.3851 & 1.4706 & -0.0855 \\
22 & 1.3696 & 1.2988 & 0.0708 \\
23 & 1.4067 & 1.5193 & -0.1126 \\
24 & 1.3449 & 1.2428 & 0.1021 \\
31 & 1.4157 & 1.4835 & -0.0678 \\
32 & 1.3862 & 1.4618 & -0.0756 \\
33 & 1.4012 & 1.4220 & -0.0208 \\
34 & 2.5086 & 2.4212 & 0.0874 \\
\hline
\end{tabular}


Turkish Comp Theo Chem (TC\&TC), 4(1), (2020), 12 - 23

Momohjimoh Idris OVAKU, Stephen Eyije ABECHI, Gideon Adamu SHALLANGWA, Adamu UZAIRU

Table 4b: Experimental, Predicted and Residual Activities for test set

\begin{tabular}{lccl}
\hline S/N & Experimental activity & Predicted activity & Residual activity \\
\hline 1 & 1.6253 & 1.2498 & 0.3755 \\
6 & 1.3546 & 1.5116 & 0.1570 \\
8 & 1.3788 & 1.3171 & 0.0617 \\
9 & & 3.3794 & 0.6206 \\
& & & \\
18 & 1.0000 & 1.4106 & 0.0466 \\
25 & 1.6635 & 1.8581 & -0.1946 \\
26 & 1.6737 & 1.5049 & 0.1688 \\
27 & 1.7904 & 1.2847 & 0.5057 \\
28 & 1.5988 & 1.3909 & 0.2079 \\
29 & 1.7011 & & 0.6708 \\
30 & 1.6946 & 1.0303 & 0.5693 \\
\hline
\end{tabular}

Table 5: Pearson's correlation, VIF and ME.

\begin{tabular}{lcccccc}
\hline \multicolumn{1}{c}{ Descriptors } & \multicolumn{9}{c}{ Inter-correlation } & VIF & $\begin{array}{l}\text { Mean } \\
\text { Effect }\end{array}$ \\
\cline { 2 - 5 } & GATS8c & maxHBd & TDB10p & RNCS & & \\
\hline GATS8c & 1 & 0.2208 & -0.2053 & 0.3934 & 1.2216 & -0.2514 \\
MaxHBd & 0.2208 & 1 & 0.0884 & 0.1704 & 1.1071 & 0.8382 \\
TDB10p & -0.2053 & 0.0884 & 1 & -0.4878 & 1.373 & 0.2425 \\
RNCS & 0.3934 & 0.1704 & -0.4878 & 1 & 1.5357 & 0.1706 \\
\hline
\end{tabular}

The result of the Variance Inflation Factor (VIF), Pearson's correlation and the Mean Effect (ME) were presented in table 5. These tests showed the relative importance of each descriptor in the model, the inter-correlation and the collinearity between the descriptors. Their low values infers that the descriptors were well chosen and the built model is said to be statistically satisfactory [26].
The Y-randomization result presented in table 6 is an external validation test conducted on the training data set to confirm the robustness of the model. The coefficient of y-randomization $c R_{p}{ }^{2}$ with value 0.8200 which is greater than the standard value reported in table 2 above clearly shows the built model is highly robust.

Table 6: Y- randomization result

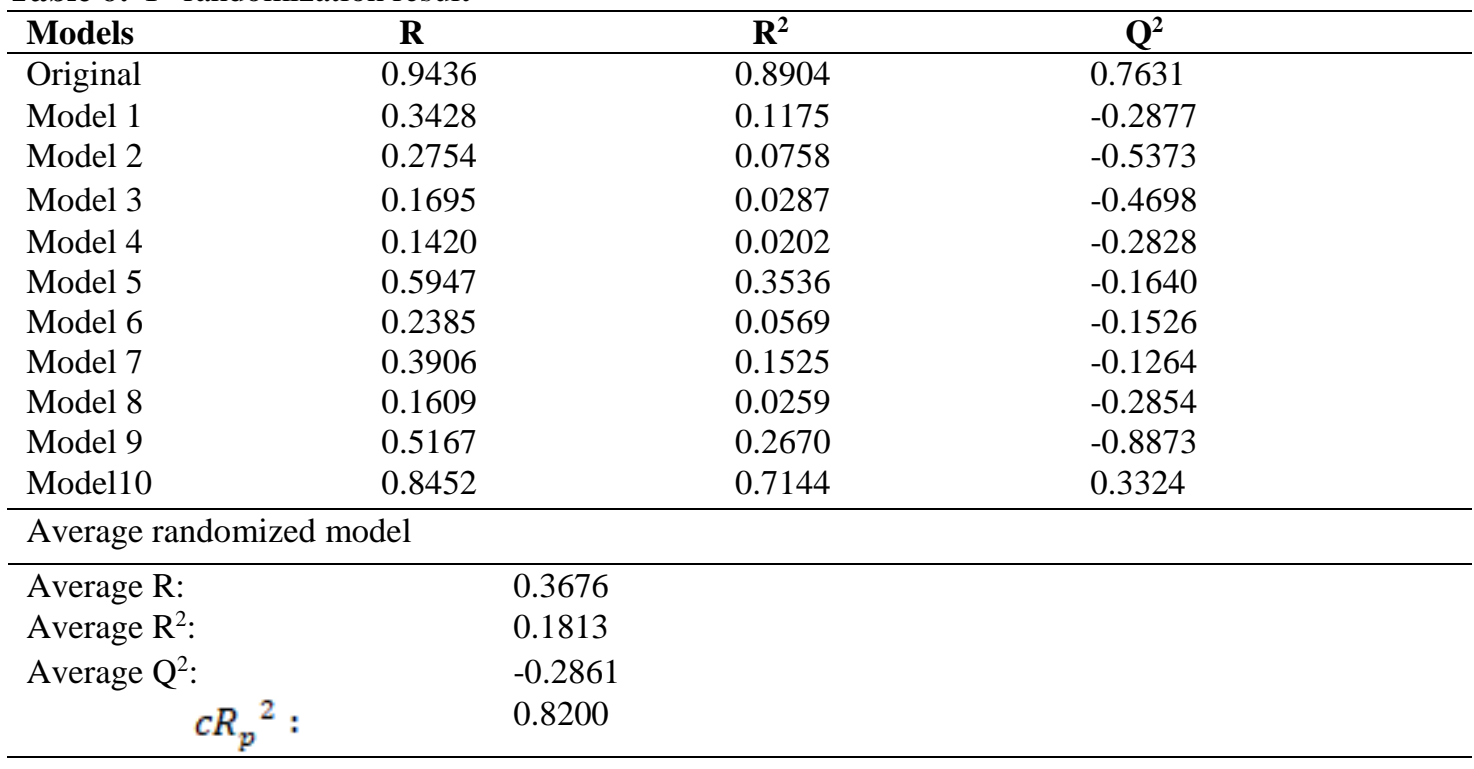


Turkish Comp Theo Chem (TC\&TC), 4(1), (2020), 12 - 23

Momohjimoh Idris OVAKU, Stephen Eyije ABECHI, Gideon Adamu SHALLANGWA, Adamu UZAIRU

Table 7: Details of the descriptors used to build the models

\begin{tabular}{lllcc}
\hline S/N & Descriptors & \multicolumn{1}{c}{ Description } & Number & Class \\
\hline 1 & GATS8c & $\begin{array}{l}\text { Geary autocorrelation - lag 8/ weighted by } \\
\text { charges } \\
\text { Maximum E-States for (strong) Hydrogen } \\
\text { Bond donors }\end{array}$ & 489 & 2D \\
3 & MaxHBd & $\begin{array}{l}\text { 3D topological distance based } \\
\text { autocorrelation - lag 10 / weighted by } \\
\text { polarizabilities } \\
\text { Relative negative charge surface area -- } \\
\text { most negative surface area * RNCG }\end{array}$ & 29 & 3D \\
4 & TDB10p & RNCS &
\end{tabular}

Table 8: Binding energy (BE) and the hydrophobicity interaction of the ligands:

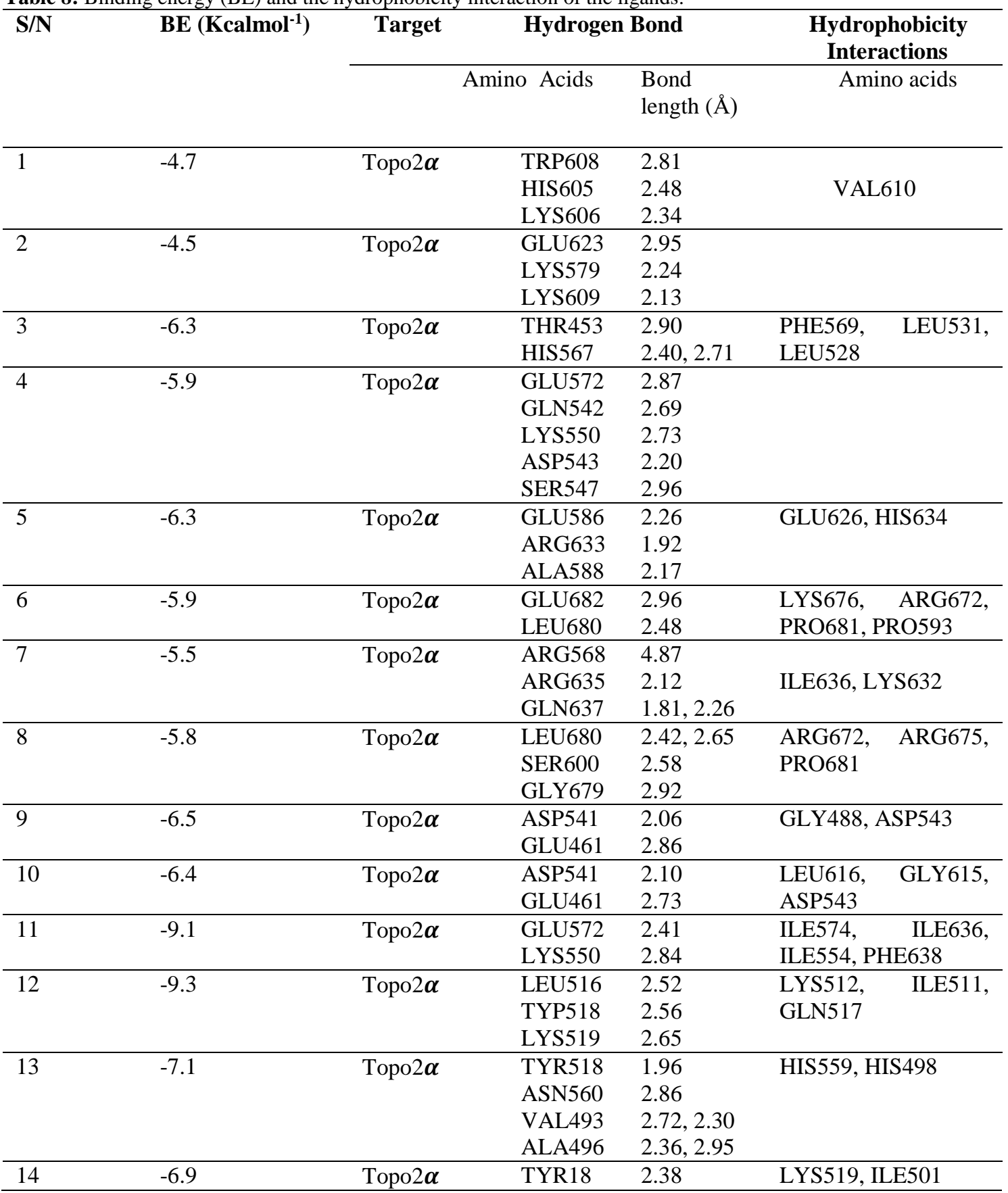


Turkish Comp Theo Chem (TC\&TC), 4(1), (2020), $12-23$

Momohjimoh Idris OVAKU, Stephen Eyije ABECHI, Gideon Adamu SHALLANGWA, Adamu UZAIRU

\begin{tabular}{|c|c|c|c|c|c|}
\hline & & & $\begin{array}{l}\text { HIS559 } \\
\text { ASN560 } \\
\text { ALA496 } \\
\end{array}$ & $\begin{array}{l}2.49 \\
2.18 \\
2.42,2.34\end{array}$ & \\
\hline 15 & -8.0 & Topo $2 \alpha$ & $\begin{array}{l}\text { ALA496 } \\
\text { ASN560 } \\
\text { HIS559 } \\
\text { VAL493 }\end{array}$ & $\begin{array}{l}2.02 \\
2.68 \\
2.07 \\
2.74\end{array}$ & ILE501, LYS519 \\
\hline 16 & -7.9 & Topo $2 \alpha$ & $\begin{array}{l}\text { ASN560 } \\
\text { ALA496 } \\
\text { HIS559 }\end{array}$ & $\begin{array}{l}2.34 \\
2.37 \\
2.04\end{array}$ & ILE501, LYS519 \\
\hline 17 & -6.7 & Topo $2 \alpha$ & $\begin{array}{l}\text { GLU682 } \\
\text { PRO593 } \\
\text { SER600 } \\
\end{array}$ & $\begin{array}{l}1.94,3.00 \\
2.57 \\
1.93 \\
\end{array}$ & ARG672, ARG675 \\
\hline 18 & -8.7 & Topo $2 \alpha$ & $\begin{array}{l}\text { GLU682 } \\
\text { GLU596 } \\
\text { LEU592 }\end{array}$ & $\begin{array}{l}2.77 \\
2.67 \\
2.72\end{array}$ & $\begin{array}{l}\text { ARG675, ARG672, } \\
\text { PRO681 }\end{array}$ \\
\hline 19 & -7.1 & Topo $2 \alpha$ & $\begin{array}{l}\text { ASN560 } \\
\text { HIS559 } \\
\text { TYR518 }\end{array}$ & $\begin{array}{l}2.25 \\
2.40 \\
2.35 \\
\end{array}$ & ILE501, LYS519 \\
\hline 20 & -7.5 & Topo $2 \alpha$ & $\begin{array}{l}\text { GLU525 } \\
\text { THR453 } \\
\text { LEU528 } \\
\text { ARG568 } \\
\text { HIS567 }\end{array}$ & $\begin{array}{l}2.42 \\
2.45 \\
3.71 \\
2.40 \\
1.97 \\
\end{array}$ & LYS529 \\
\hline 21 & -7.2 & Topo $2 \alpha$ & $\begin{array}{l}\text { ASP543 } \\
\text { GLN542 } \\
\text { SER547 } \\
\text { LYS550 } \\
\text { GLU572 }\end{array}$ & $\begin{array}{l}2.63 \\
2.55 \\
2.27 \\
2.36 \\
3.03\end{array}$ & ILE577 \\
\hline 22 & -8.3 & Topo $2 \alpha$ & ALA648 & 2.65 & $\begin{array}{l}\text { ALA652, LEU565, } \\
\text { ILE554, PHE653 }\end{array}$ \\
\hline 23 & -7.4 & Topo $2 \alpha$ & & & $\begin{array}{lr}\text { ASP645, } & \text { ALA648, } \\
\text { ILE554, } & \text { ILE649 } \\
\text { LEU565, } & \text { LYS550, } \\
\text { PHE653 } & \end{array}$ \\
\hline 24 & -6.9 & Topo $2 \alpha$ & LYS639 & 2.75 & $\begin{array}{l}\text { ALA652, } \\
\text { LHE655, } \\
\text { ILE554, PHE638 }\end{array}$ \\
\hline 25 & -6.2 & Topo $2 \alpha$ & $\begin{array}{l}\text { ALA465 } \\
\text { ASP541 } \\
\text { ASP543 } \\
\text { LYS614 }\end{array}$ & $\begin{array}{l}2.61 \\
2.64 \\
2.22,2.59 \\
2.40,2.83\end{array}$ & GLU461 \\
\hline 26 & -6.9 & Topo $2 \alpha$ & $\begin{array}{l}\text { GLY617 } \\
\text { LEU616 } \\
\text { ASP541 } \\
\text { ASP543 }\end{array}$ & $\begin{array}{l}2.08 \\
3.03 \\
4.98 \\
2.18\end{array}$ & GLU461 \\
\hline 27 & -7.1 & Topo $2 \boldsymbol{\alpha}$ & $\begin{array}{l}\text { ASP630 } \\
\text { TYR590 } \\
\text { GLU586 } \\
\text { GLU626 }\end{array}$ & $\begin{array}{l}2.77 \\
2.94 \\
2.71 \\
5.30\end{array}$ & ALA629 \\
\hline 28 & -7.1 & Topo $2 \boldsymbol{\alpha}$ & $\begin{array}{l}\text { ASP630 } \\
\text { TYR590 } \\
\text { GLU586 } \\
\text { GLU626 }\end{array}$ & $\begin{array}{l}2.83 \\
2.51 \\
4.39 \\
2.95\end{array}$ & ALA629 \\
\hline 29 & -7.0 & Topo $2 \alpha$ & $\begin{array}{l}\text { ALA588 } \\
\text { GLU586 } \\
\text { ARG633 }\end{array}$ & $\begin{array}{l}2.99 \\
2.38 \\
2.39\end{array}$ & $\begin{array}{ll}\text { HIS634, } & \text { PHE589, } \\
\text { MET587 } & \end{array}$ \\
\hline
\end{tabular}


Turkish Comp Theo Chem (TC\&TC), 4(1), (2020), $12-23$

Momohjimoh Idris OVAKU, Stephen Eyije ABECHI, Gideon Adamu SHALLANGWA, Adamu UZAIRU

\begin{tabular}{|c|c|c|c|c|c|}
\hline & & & $\begin{array}{l}\text { TYR590 } \\
\text { LYS579 }\end{array}$ & $\begin{array}{l}2.21,2.70 \\
2.71\end{array}$ & \\
\hline \multirow[t]{4}{*}{30} & -7.4 & Topo $2 \alpha$ & GLU589 & 2.60 & ALA629 \\
\hline & & & GLU626 & $2.62,2.56$ & \\
\hline & & & ASP630 & 2.52 & \\
\hline & & & TYR590 & 2.59 & \\
\hline \multirow[t]{3}{*}{31} & -8.9 & Topo $2 \alpha$ & HIS559 & 2.01 & PRO562 \\
\hline & & & TYR518 & 2.43 & \\
\hline & & & ASN560 & 2.36 & \\
\hline \multirow[t]{3}{*}{32} & -8.2 & Topo $2 \alpha$ & HIS559 & $1.98,2.45$ & ILE501 \\
\hline & & & ASN560 & 2.43 & \\
\hline & & & TYR518 & 2.70 & \\
\hline \multirow[t]{3}{*}{33} & -8.2 & Topo $2 \alpha$ & HIS567 & 3.03 & LEU528 \\
\hline & & & THR453 & 2.34 & LEU531 \\
\hline & & & & & PHE569 \\
\hline \multirow[t]{2}{*}{34} & -8.1 & Topo $2 \alpha$ & LYS639 & 3.04 & PHE638, \\
\hline & & & ALA648 & 2.59 & ILE, \\
\hline \multirow[t]{4}{*}{ Doxorubicin } & -6.8 & Topo $2 \alpha$ & LEU516 & 2.39 & GLN517, ARG532 \\
\hline & & & ASN433 & 2.00 & \\
\hline & & & THR530 & 2.95 & \\
\hline & & & LYS520 & 2.95 & \\
\hline
\end{tabular}

Figure 2 and 3 represent the plot of predicted activity against experimental activity for both training set and test set. The square correlation coefficient $R^{2}$ values for the two plots were greater than 0.5 which passed the minimum requirement for a good QSAR model.

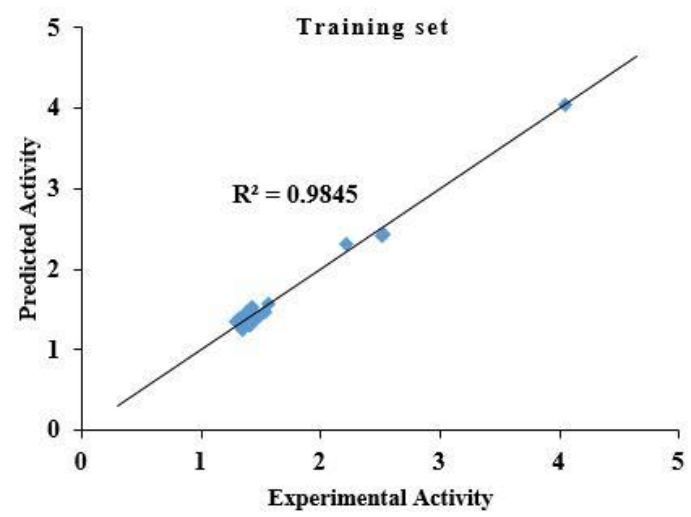

Figure 2: Plot of predicted activity against experimental activity for training set.

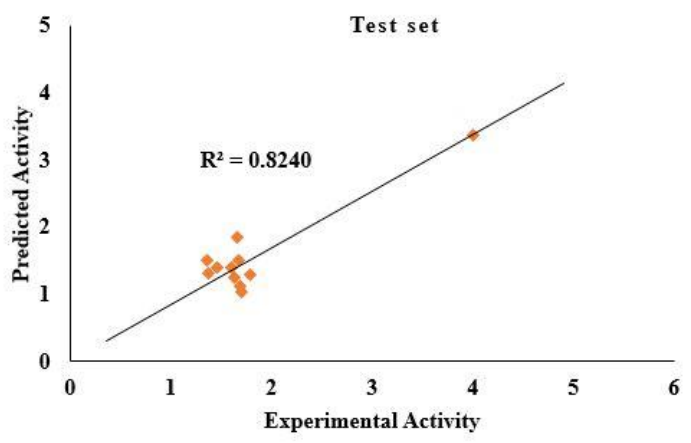

Figure 3. Plot of predicted activity against experimental activity for test set.

Figure 4 show the plot of standardized residual activity against the leverages, this plot is otherwise called Williams plot. This plot basically helps to illustrate the outliers and influential compounds and in this work there were four whose leverage value goes beyond the calculated warning leverage $\left(\boldsymbol{l}^{*}=\right.$ 0.65), and were treated as outliers. Figure 5 display the plot of standardized residual against the experimental activity and for the fact that the scattered plot were all within the base line of the graph, it indicate that there are no significant systematic error. 


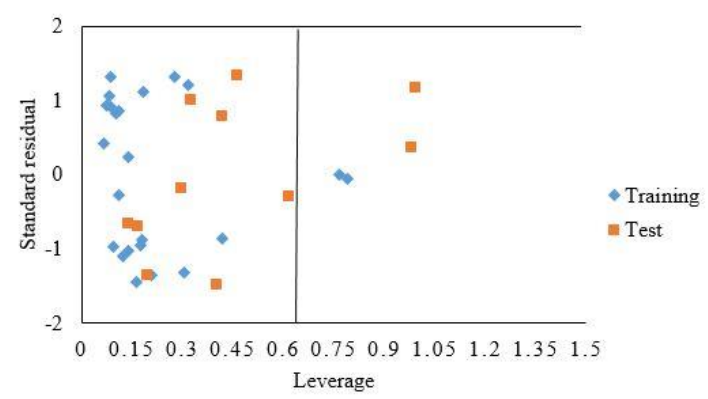

Figure 4: Plot of standardize residual against leverages.

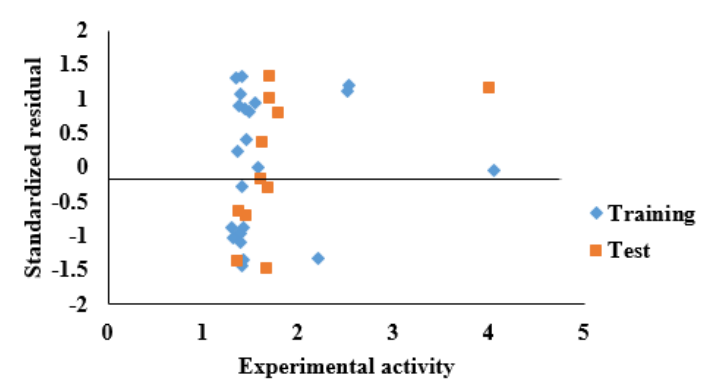

Figure 5: Plot of standardize residual against Experimental activity.

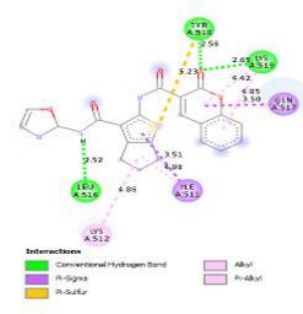

(a) $2 \mathrm{D}$ interaction of ligand 12 .

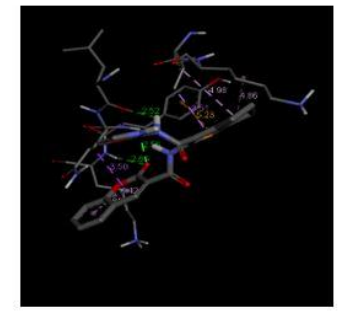

(b) 3D interaction of ligand 12
Figure 6: 2D and 3D interaction of ligand 12.

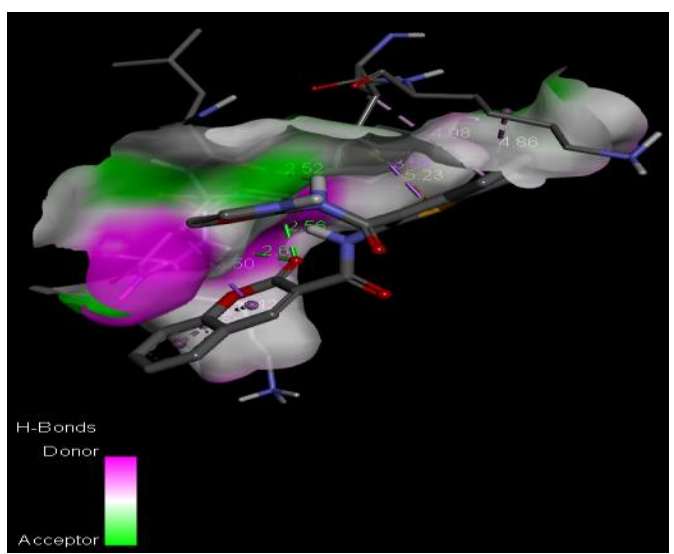

Figure 7: Hydrogen interaction of ligand 12.

Table 7 present the class and nature of the descriptors used to build the model, while table 8 clearly shows the binding energy, hydrogen Bond and Hydrophobicity interactions of the complex. In the table, it clearly shows that the ligands have binding energy that ranges from $-4.5 \mathrm{kcal} / \mathrm{mol}$ to $9.3 \mathrm{kcal} / \mathrm{mol}$. Ligand 12 was found to have the highest binding energy of $-9.3 \mathrm{kcal} / \mathrm{mol}$ and bind strongly into the pocket of the receptor than the reference drug Doxorubicin with $-6.8 \mathrm{kcal} / \mathrm{mol}$ binding energy. The visualized $2 \mathrm{D}$ and $3 \mathrm{D}$ structure of ligand 12 is presented as figure 6. Figure 7 however present the hydrogen bond interaction between ligand 12 and topo $2 \boldsymbol{\alpha}$, this shows three hydrogen bond interaction of bond lengths $2.52 \AA$, $2.56 \AA$, and $2.65 \AA$ with LEU516, TYP518 and LYS519 amino acid residues of the target and also three hydrophobicity interaction with LYS512, ILE511 and GLN517 of the target site. The N-H in the 2-methyloxazol-amine of ligand 12, acts as hydrogen acceptor and formed a hydrogen bond with LEU516 of the target. While the $\mathrm{C}=\mathrm{O}$ in the $2 \mathrm{H}$-chromen-2-one of the ligand acts as hydrogen donor and formed two hydrogen bond with TYR518 and LYS519 of the target.

\section{Conclusion}

This work has successfully built a good and robust QSAR model that passed all the minimum recommendations for building a good QSAR model. The Williams plot however pointed out four compounds out of the 34 compounds as outliers and may not be considered when designing a new antibreast cancer agents from the derivatives. Conclusively ligand 12 with the highest binding energy can serve as better drug against breast cancer.

\section{References}

[1] H. Frankish, 15 Million new cancer cases per year by 2020, says WHO: Lancet. (2003) 361, 1278-1287, DOI: $\quad 10.1016 / \mathrm{S} 0140-$ 6736(03)13038-3.

[2] H.D. Nelson, M.E. Smith, J.C. Griffin, R. Fu, Use of medications to reduce risk for primary breast cancer: a systematic review for the U.S. Preventive Services Task Force. Annals of Internal Medicine 158 (2013) 604-14.

[3] M.N. Okobia, C.H. Bunker, F.E. Okonofua and U. Osime Knowledge, Attitude and Practice of Nigerian Women towards Breast Cancer: A Cross-Sectional Study. World Journal of Surgical Oncology. 4 (2006) 1115.

[4] Rathod, Antifungal and Antibacterial activities of Imidazolyl pyrimidines 
derivatives and their QSAR Studies under Conventional and Microwave-assisted, Int J PharmTech Res. 3 (2011) 1942-1951.

[5] Y. Pommier, E. Leo, H. Zhang, and C. Marchand, DNA Topoisomerases and Their Poisoning by Anticancer and Antibacterial Drugs, Chem. Biol. 17 (2010) 421-433.

[6] Y. Pommier, Y. Sun, S.N. Huang, and J.L. Nitiss, Roles of Eukaryotic Topoisomerases in Transcription, Replication and Genomic Stability, Nat. Rev. Mol. Cell Biol. 17 (2016) 703-721.

[7] J.E. Deweese, and N. Osheroff, The DNA Cleavage Reaction of Topoisomerase II: Wolf in Sheep's Clothing. Nucleic Acids Res. 37 (2009) 738-749.

[8] P. Forterre, and D. Gadelle, Phylogenomics of DNA Topoisomerases: Their Origin and Putative Roles in the Emergence of Modern Organisms, Nucleic Acids Res. 37 (2009) 679-692.

[9] B. Mukesh, and K. Rakesh, Molecular Docking: A Review. IJRAP, 2 (2011)17461751.

[10] I.A. Guedes, C.S. de Magalhães and L.E. Dardenne, Receptor-Ligand Molecular Docking: Biophysical Reviews. (2014) 6 7587

[11] Albratty, M., El-Sharkawy, K. A., and Alam, S., (2017). Synthesis and Antitumor Activity of Some Novel Thiophene, Pyrimidine, Coumarine, Pyrazole and Pyridine Derivatives. Acta Pharm. 67, 15-33, DOI: 10.1515/acph-2017-0004.

[12] Z. Li, H. Wan, Y. Shi, P. Ouyang, Personal experience with four kinds of chemical structure drawing software: review on ChemDraw, ChemWindow, ISIS/Draw, and ChemSketch, Journal of Chemical Information and Computer Sciences. 44 (2004) 1886-1890.

[13] C. Lee, W. Yang, R.G. Parr, Development of the Colle-Salvetti correlation-energy formula into a functional of the electron density, Physical Review B. 37 (1988) 785.

[14] A.D. Becke, Becke's three parameter hybrid method using the LYP correlation functional, J. Chem. Phys. 98 (1993) 5648- 5652.

[15] S.E. Adeniji, S. Uba, A. Uzairu, In Silico Study For Investigating and Predicting the activities of 1,2,4-triazole derivaties as potent anti-tubercular agents, The Journal of Engineering and Exact Sciences. 4 (2018) 246-254.

[16] P. Singh, Quantitative Structure-Activity Relationship Study of Substituted-[1, 2, 4] Oxadiazoles as S1P1 Agonists, Journal of Current Chemical and Pharmaceutical Sciences. 3 (2013) 334-345.

[17] G. Melagraki, A. Afantitis, K. Makridima, H. Sarimveis, O. Igglessi-Markopoulou, Prediction of toxicity using a novel RBF neural network training methodology, Journal of Molecular Modeling. 12 (2006) 297-305.

[18] A. Afantitis, G. Melagraki, H. Sarimveis, P.A. Koutentis, J. Markopoulos, O. IgglessiMarkopoulou, A novel QSAR model for predicting induction of apoptosis by 4aryl4H-chromenes, Bioorganic \& Medicinal Chemistry. 14 (2006) 6686-6694.

[19] A.K. Chakraborti, B. Gopalakrishnan, M.E. Sobhia, A. Malde, 3D-QSAR studies of indole derivatives as phosphodiesterase IV inhibitors, European Journal of Medicinal Chemistry. 38 (2003) 975-982.

[20] K.F. Khaled, Modeling corrosion inhibition of iron in acid medium by genetic function approximation method: A QSAR model, Corrosion Science. 53 (2011) 3457-3465.

[21] A. Tropsha, P. Gramatica, V.K. Gombar, The importance of being earnest: validation is the absolute essential for successful application and interpretation of QSPR models. Mol. Inform. 22, 69-77, 2003, DOI: 10.1002/qsar.200390007.

[22] N. Minovski, Š. Župerl, V. Drgan, M. Novič, Assessment of applicability domain for multivariate counter-propagation artificial neural network predictive models by minimum Euclidean distance space analysis: a case study, Anal. Chim. Acta 759 (2013) 2842.

[23] R. Veerasamy, H. Rajak, A. Jain, S. Sivadasan, C.P. Varghese, R.K. Agrawal, Validation of QSAR models-strategies and importance, International Journal of Drug Design \& Discovery. 3 (2011) 511-519.

[24] A. Tropsha, P. Gramatica, V. K. Gombar, The importance of being earnest: validation is the absolute essential for successful application 
Turkish Comp Theo Chem (TC\&TC), 4(1), (2020), $12-23$

Momohjimoh Idris OVAKU, Stephen Eyije ABECHI, Gideon Adamu SHALLANGWA, Adamu UZAIRU

and interpretation of QSPR models,

Molecular Informatics. 22 (2003) 69-77.

[25] http://www.rcsb.org/pdb/home/home.do

[26] S.E. Adeniji, S. Uba, A. Uzairu, QSAR

Modeling and Molecular Docking Analysis of

Some Active Compounds against

Mycobacterium tuberculosis Receptor (Mtb

CYP121), Journal of Pathogens. (2018) 1-24. 